\title{
Training Status and Gender Effects on Sternocleidomastoid and Abdominal Muscles Activity during Curl-Up Exercise with Different Respiratory Cycle
}

\author{
Hasan Sözen \\ Ordu University, Department of Physical Education and Sport, Ordu, Turkey. \\ Received: 28 September 2016, Accepted: 08 December 2016, Published online: 25 April 2017 \\ (C) Ordu University Institute of Health Sciences, Turkey, 2017
}

\begin{abstract}
Objective: This study aims to investigate sternocleidomastoid muscle (SCM) during curl-up exercise with different inspiration and expiration cycle among subject with different training status and gender, and the abdominal muscles in the targeted area.

Methods: 24 healthy subjects volunteered to participate in the study. The data were gathered from bilateral SCM, rectus abdominis (RA), external oblique (EO) and transversus abdominis/internal oblique (TrA/IO) muscles via surface electromyography (EMG).

Results: The analysis of all the data gathered from the participants shows that the muscle activation in EO right, TrA/IO right, TrA/IO left and RA right during curl-up exercise with expiration is higher than activation during curl-up exercise with inspiration. A comparison of sedentary and mean scores of participants during curl-up exercise with expiration did not reveal any significant difference. A comparison of mean scores of men and women during curl-up exercise with expiration showed that the scores derived from females' EO left and RA right muscles is higher than the scores derived from the same muscles group of males. However, when the average scores of male and female participants in the curl-up movement with inspiration were compared, the scores derived from the same muscle group of females is higher than that of males'.

Conclusion: As there is no difference between genders and the contraction rates of SCM muscle, no gender-specific suggestions can be made about respiration during curl-up for the health of neck and cervical zone

Key words: Curl-up exercise, abdominal muscles, sternocleidomastoid, electromyography.

Address for correspondence/reprints:

\section{Hasan Sözen}

Telephone number: +90 5327849129

E-mail: sozenhasan@yahoo.com,

hasansozen@odu.edu.tr

DOI: $10.19127 / \mathrm{mbsjohs.309373}$

\section{Introduction}

Exercise and sport scientists and experts of sport medicine acknowledge that abdominal muscle is an important element for health and success in athletic performance. Abdominal muscles are also essential for proper alignment of axial skeleton, daily life and activities such as work or athletic performance in supporting extreme upper and lower movement (Hildenbrand and Noble, 2004). Therefore, weak abdominal muscle strength causes disruption of balance of the body. Particularly stability in pelvic girdle and its unison between the limbs depend on abdominal muscle strength and endurance (Lahad et al.1994). Backache, one of the physical
\end{abstract}


problems seen frequently amongst adults in industrialized societies, is regarded as a serious health problem, and it is known to be caused by lower abdominal muscles which are highly weakened or used poorly or incorrectly in daily life. Many researchers emphasize the importance of abdominal muscle in both postural control and waist injury (Janda and Schmid 1980; Foster and Fulton 1991; Rodriguez et al. 1992; Johannsen et al. 1995; McGill 1998; Garcia et al. 2000; Critchley et al. 2011; Hides et al. 2011).

As abdominal muscle is the central point of the body, the importance of abdominal muscle is great for each sport branch. An average sportsman takes care to work on abdominal muscles sufficiently in comparison to other muscle group (Beim et al. 1997). Although abdominal muscle group is important, incorrect training methods used to develop these muscle groups may cause harm for spinal health (Norris 1993).

As can be seen, body balance which is highly important for daily life and sportive activities can be brought up to optimum level by strengthening abdominal muscles. Exercise types performed to strengthen abdominal muscles are inadequate and the most common exercise type is curl-up. That is why, curl -up has been the center of attention for researchers for decades. One of the most important points in the research on curl-up is the health of spinal cord and strengthening abdominal muscles by including the spinal cord to the movement at the minimum level. Therefore, researchers interested in health and sport sciences put emphasis on curl-up's muscle activation which is done on condition of stabilizing lumber spine of the subjects who do sports for health or performance (Axler and McGill 1997; Yoon et al. 2014). Otherwise, failing to stabilize lumber spine zone leads to serious injuries on waist and strain during the exercise which is done to train abdominal muscles, especially transversus abdominis/internal oblique (TrA/IO) muscles because of its anatomy (Hodges 2003; Goldby et al. 2006). In practice, the strengthening exercises which are strength-oriented for the abdominal zone vary a lot. Abdominal curl-up is frequently used for strengthening abdominal muscles and stabilization of lumbar zone in sport sciences and rehabilitation programs (Axler and McGill 1997).

Cervical spine is covered by complex regulation of muscles which contribute to static and dynamic control of head and neck (Falla et al. 2004). During deep cervical flexion longus capitis and longus colli supply segmental stabilization and support to cervical spine (Kelly et al. 2013). Sternocleidomastoid muscle has primary importance in the control of the head position by holding mastoid process and occiput. Superficial cervical flexors like sternocleidomastoid and front scalene muscle play a great role for cervical stabilization (O'Leary et al. 2007). Sternocleidomastoid muscle is directly stimulated by the cervical segments of spinal accessory nerve and cervical C2, C3 and C4. This muscle has a great role in important pathologies like headache and vertigo (Clark et al. 1993). As seen in certain studies, when the neck is stabilized, activation of neck flexor muscle is higher in the subjects having cervical pain when compared to healthy subjects (Jull 2000; Sterling et al. 2001). During curl-up, SCM muscle is suitable for redundant use. However, during curl-up exercises targeting abdominal muscles, along with unnecessary strain of SCM muscle, neck and spinal cord strains may occur. SCM becomes more active in situations where respiration is more frequent, such as respiration against a force, like coughing (Adams et al. 1989; Elvis 2008; Neumann 2009). Therefore, respiration type (expiration-inspiration) which occurs at the moment of strain during curl-up may cause SCM muscle strain at different levels. Nevertheless, the number of studies examining the activities of SCM muscles in different respiration types during curl-up exercises is not sufficient in the literature.

The hypothesis of this study is the idea that there is a difference in the inspiration and expiration by subjects with different sportive capacities and gender during curl-up, and in the participation level of SCM muscles and abdominal muscles in the target area during the activity. Therefore, this study investigates inspiration and expiration done during curl-up in the subjects with different sport capacities and sexes, and the participation of SCM muscles and abdominal muscles in the target area during exercise.

\section{Methods}

\section{Study participants}

Twenty-four healthy volunteer subjects (12 male (6 sedentary, 6 athlete); 12 female ( 6 sedentary, 6 athlete)) participated in the study (Table 1). All participants approved the volunteering form approved by the University of Ordu Ethical Committee. 
Table 1. General Characteristics of Subjects

\begin{tabular}{lccc}
\hline Variables & Male $(\mathrm{n}=12)$ & $\begin{array}{c}\text { Female } \\
(\mathrm{n}=12)\end{array}$ & $\begin{array}{c}\text { Total } \\
(\mathrm{n}=24)\end{array}$ \\
\hline Age (years) & $20.3 \pm 1.3$ & $20.9 \pm 2.8$ & $20.6 \pm 2.2$ \\
Height $(\mathrm{cm})$ & $176.7 \pm 3.8$ & $172.6 \pm 6.8$ & $174.6 \pm 5.8$ \\
Weight $(\mathrm{kg})$ & $71.7 \pm 8.3$ & $58.0 \pm 8.1$ & $64.8 \pm 10.6$ \\
BMI $\left(\mathrm{kg} / \mathrm{m}^{2}\right)$ & $22.9 \pm 2.6$ & $19.4 \pm 1.9$ & $21.1 \pm 2.9$
\end{tabular}

Abbreviations: BMI; body mass index

Values are presented as mean $\pm \mathrm{SD}$.

\section{Procedure and Measurements}

Bilaterally silver/silver chlorine (Ag/AgCI) bipolar surface electromyography electrodes (Blue Sensor P-00-S Ambu, Denmark) were placed bilateral on the central points of rectus abdominis (RA), external oblique (EO), transversus abdominis/internal oblique (TrA/IO), and sternocleidomastoid (SCM) muscle in a parallel fashion to their muscle fibrils. Before the electrodes were placed, they were cleaned with an alcohol solution to prevent artefacts, and the skin was shaved to make it smooth (Konrad 2005; De Luca 2008; Criswell 2011). External gel was not used as electrodes placed on the muscles already had gel on them. Cables and electrodes were fixed with plaster to prevent the formation of any artefact during curlup. ME 6000 (Mega Electronics Ltd, FI-70460, Kuopio, Finland) portable EMG device was used to measure muscle activation. After electrode placement finished, MVIC values for each 5 seconds were gathered from each muscle (RA, EO, TrA/IO and SCM). MVIC values were collected to normalize EMG data derived during curl-up. Data sampling speed was arranged as $1000 \mathrm{~Hz}$. The rootmean-square (RMS) value was calculated in EMG records software program (Mega Win 3.0).

\section{Training Procedure}

At the beginning of curl-up, legs were on the floor, knees bent $90 \mathrm{o}$ and thumbs near ears, hands in the air near the head. Participants did the exercise until their heads, shoulders and scapulae broke contact off the ground. A target bar was placed above participants' chest line so that each participant completed the exercise with the same angle (until scapulae was off the ground), and each participant was asked to touch the bar in every repetition of the exercise (Hildenbrand and Noble 2004; Yoon et al. 2014). Participants did the curl- up at two different phases of respiration and two different stages: (one set 10 repetitions) and inspiration (one set 10 repetitions). Each curl-up repetition (head, shoulders, and scapulae breaking contact off the ground respectively) took 3 seconds in inspiration or expiration. Participant's movement started with a set of inspiration with 10 repetition or a set of expiration with 10 repetition, and they paused for a 30-minute break at the end of the each set before moving on to the other respiration phase so that muscle tiredness could be averted.

\section{Statistical analysis}

For all statistical analysis, the mean scores of the percentage of values gathered from muscles during one set 10 repetition curl-up with inspiration or expiration to the values of MVIC. KolmogorovSmirnov Z-test was performed to investigate whether continuous data approximated a normal distribution and a paired t-test was used to compare the differences in normalized EMG muscle activity of the bilateral SCM, RF, EO, and TrA/IO muscles between abdominal curl-up with inspiration and expiration in all subjects, training status and gender status. The level of significance was $\mathrm{p}<0.05$. SPSS 16.0 software was used for all data analysis (SPSS, Inc., an IBM Company, Chicago, Illinois, USA).

\section{Results}

All of the continuous variables were found to approximate a normal distribution (KolmogorovSmirnov Z test, $p>$.05).

There was significantly lower EMG activity of right EO, $33.56 \pm 10.315 \% \mathrm{MVIC}$; right $\mathrm{TrA} / \mathrm{IO}, 26.14 \pm$ $9.771 \% \mathrm{MVIC}$; left TrA/IO, $31.42 \pm 10.573$ \%MVIC; right RA $31.87 \pm 8.535 \%$ MVIC; left RA $32.30 \pm 7.647 \% \mathrm{MVIC}$ and greater EMG activity of right SCM, $29.58 \%$ MVIC 11.887; left SCM, 28.39 $\% 12.226 \%$ MVIC during abdominal curl-up with inspiration compared with the EMG activity of right EO, $34.97 \pm \% \mathrm{MVIC}$; right $\mathrm{TrA} / \mathrm{IO}, 28.13 \pm$ $9.933 \%$ MVIC; left $\mathrm{TrA} / \mathrm{IO}, 32.74 \pm 9.812$ \%MVIC; right RA $33.79 \pm 8.828 \% \mathrm{MVIC}$; left RA $34.36 \pm 7.897 \%$ MVIC and right SCM $27.23 \pm$ $9.924 \%$ MVIC; left SCM $25.53 \pm 10.763 \%$ MVIC during abdominal curl-up with expiration $(* \mathrm{p}<.05)$ (Table 2). 
Table 2. Comparing abdominal curl-up with expiration and inspiration in all subjects.

\begin{tabular}{|c|c|c|c|c|c|c|}
\hline Muscle & $\begin{array}{l}\text { Type of } \\
\text { respiration }\end{array}$ & $\mathrm{N}$ & M & SD & $\mathrm{t}$ & $\mathrm{p}$ \\
\hline \multirow[b]{2}{*}{ EO right } & Expiration & \multirow[b]{2}{*}{24} & 34.97 & 10.359 & \multirow[b]{2}{*}{2.401} & \multirow[b]{2}{*}{$.021 *$} \\
\hline & Inspiration & & 33.56 & 10.315 & & \\
\hline \multirow{2}{*}{ EO left } & Expiration & \multirow{2}{*}{24} & 39.17 & 18.669 & \multirow{2}{*}{1.351} & \multirow{2}{*}{.184} \\
\hline & Inspiration & & 37.93 & 19.023 & & \\
\hline \multirow{2}{*}{$\begin{array}{l}\mathrm{TrA} / \mathrm{IO} \\
\text { right }\end{array}$} & Expiration & \multirow{2}{*}{24} & 28.13 & 9.933 & \multirow{2}{*}{3.362} & \multirow{2}{*}{$.002 *$} \\
\hline & Inspiration & & 26.14 & 9.771 & & \\
\hline \multirow{2}{*}{$\begin{array}{l}\text { TrA/IO } \\
\text { left }\end{array}$} & Expiration & \multirow{2}{*}{24} & 32.74 & 9.812 & \multirow{2}{*}{2.169} & \multirow{2}{*}{$.036^{*}$} \\
\hline & Inspiration & & 31.42 & 10.573 & & \\
\hline \multirow{2}{*}{ RA right } & Expiration & \multirow{2}{*}{24} & 33.79 & 8.828 & \multirow{2}{*}{3.785} & \multirow{2}{*}{$.001 *$} \\
\hline & Inspiration & & 31.87 & 8.535 & & \\
\hline \multirow{2}{*}{ RA left } & Expiration & \multirow{2}{*}{24} & 34.36 & 7.897 & \multirow{2}{*}{3.674} & \multirow{2}{*}{$.001 *$} \\
\hline & Inspiration & & 32.30 & 7.647 & & \\
\hline \multirow{2}{*}{$\begin{array}{l}\text { SCM } \\
\text { right }\end{array}$} & Expiration & \multirow{2}{*}{24} & 27.23 & 9.924 & \multirow{2}{*}{-3.503} & \multirow{2}{*}{$.001 *$} \\
\hline & Inspiration & & 29.58 & 11.887 & & \\
\hline \multirow{2}{*}{ SCM left } & Expiration & \multirow{2}{*}{24} & 25.53 & 10.763 & \multirow{2}{*}{-5.064} & \multirow{2}{*}{$.000 *$} \\
\hline & Inspiration & & 28.39 & 12.226 & & \\
\hline
\end{tabular}

There was only significantly lower EMG activity of left RA, $31.43 \pm 7.433 \%$ MVIC during abdominal curl-up with expiration in athletes subjects compared with the EMG activity of left RA, 37.29

$\pm 7.396 \%$ MVIC during abdominal curl-up with expiration in sedentary subjects $(* \mathrm{p}<.05)$ (Table $3)$. 
Table 3. Comparing abdominal curl-up with expiration in training status.

\begin{tabular}{|c|c|c|c|c|c|c|}
\hline Muscle & $\begin{array}{l}\text { Training } \\
\text { Status }\end{array}$ & $\mathrm{N}$ & M & SD & $\mathrm{t}$ & $\mathrm{p}$ \\
\hline \multirow{2}{*}{ EO right } & Sedentary & 12 & 33.86 & 10.330 & \multirow{2}{*}{-.674} & \multirow{2}{*}{.504} \\
\hline & Athlete & 12 & 36.08 & 10.533 & & \\
\hline \multirow{2}{*}{ EO left } & Sedentary & 12 & 35.78 & 15.956 & \multirow{2}{*}{-1.155} & \multirow{2}{*}{.255} \\
\hline & Athlete & 12 & 42.57 & 20.895 & & \\
\hline \multirow{2}{*}{ TrA/IO right } & Sedentary & 12 & 30.58 & 7.171 & \multirow{2}{*}{1.589} & \multirow{2}{*}{.120} \\
\hline & Athlete & 12 & 25.68 & 11.769 & & \\
\hline \multirow{2}{*}{ TrA/IO left } & Sedentary & 12 & 34.54 & 8.251 & \multirow{2}{*}{1.163} & \multirow{2}{*}{.252} \\
\hline & Athlete & 12 & 30.95 & 11.080 & & \\
\hline \multirow{2}{*}{ RA right } & Sedentary & 12 & 35.59 & 7.438 & \multirow{2}{*}{1.297} & \multirow{2}{*}{.202} \\
\hline & Athlete & 12 & 32.00 & 9.892 & & \\
\hline \multirow{2}{*}{ RA left } & Sedentary & 12 & 37.29 & 7.396 & \multirow{2}{*}{2.498} & \multirow{2}{*}{$.017 *$} \\
\hline & Athlete & 12 & 31.43 & 7.433 & & \\
\hline \multirow{2}{*}{ SCM right } & Sedentary & 12 & 28.68 & 8.133 & \multirow{2}{*}{.923} & \multirow{2}{*}{.362} \\
\hline & Athlete & 12 & 25.78 & 11.472 & & \\
\hline \multirow{2}{*}{ SCM left } & Sedentary & 12 & 27.04 & 8.901 & \multirow{2}{*}{.884} & \multirow{2}{*}{.382} \\
\hline & Athlete & 12 & 24.02 & 12.400 & & \\
\hline
\end{tabular}

There was no significantly EMG activity during abdominal curl-up with expiration between athletes and sedentary subjects (Table 4). 
Table 4. Comparing abdominal curl-up with inspiration in training status.

\begin{tabular}{|c|c|c|c|c|c|c|}
\hline Muscle & Training Status & $\mathrm{N}$ & M & $\mathrm{SD}$ & $\mathrm{t}$ & $\mathrm{p}$ \\
\hline \multirow{2}{*}{ EO right } & Sedentary & 12 & 31.71 & 9.556 & \multirow{2}{*}{-1.141} & \multirow{2}{*}{.261} \\
\hline & Athlete & 12 & 35.41 & 10.947 & & \\
\hline \multirow{2}{*}{ EO left } & Sedentary & 12 & 32.88 & 15.034 & \multirow{2}{*}{-1.722} & \multirow{2}{*}{.093} \\
\hline & Athlete & 12 & 42.99 & 21.518 & & \\
\hline \multirow{2}{*}{ TrA/IO right } & Sedentary & 12 & 28.53 & 8.759 & \multirow{2}{*}{1.577} & \multirow{2}{*}{.123} \\
\hline & Athlete & 12 & 23.75 & 10.354 & & \\
\hline \multirow{2}{*}{ TrA/IO left } & Sedentary & 12 & 32.99 & 9.151 & \multirow{2}{*}{.941} & \multirow{2}{*}{.353} \\
\hline & Athlete & 12 & 29.84 & 11.853 & & \\
\hline \multirow{2}{*}{ RA right } & Sedentary & 12 & 32.81 & 6.846 & \multirow{2}{*}{.695} & \multirow{2}{*}{.491} \\
\hline & Athlete & 12 & 30.92 & 10.038 & & \\
\hline \multirow{2}{*}{ RA left } & Sedentary & 12 & 34.39 & 6.013 & \multirow{2}{*}{1.775} & \multirow{2}{*}{.084} \\
\hline & Athlete & 12 & 30.21 & 8.642 & & \\
\hline \multirow{2}{*}{ SCM right } & Sedentary & 12 & 30.16 & 8.958 & \multirow{2}{*}{.303} & \multirow{2}{*}{.763} \\
\hline & Athlete & 12 & 29.01 & 14.461 & & \\
\hline \multirow{2}{*}{ SCM left } & Sedentary & 12 & 29.59 & 9.520 & \multirow{2}{*}{.619} & \multirow{2}{*}{.540} \\
\hline & Athlete & 12 & 27.18 & 14.598 & & \\
\hline
\end{tabular}

There was significantly lower EMG activity of left EO, $30.69 \pm 16.037 \%$ MVIC ; right RA, $30.26 \pm$ $8.404 \%$ MVIC during abdominal curl-up with expiration in male compared with the EMG activity of left EO, $47.66 \pm 17.511 \% \mathrm{MVIC}$; right RA, $37.32 \pm 7.945 \%$ MVIC during abdominal curlup with expiration in female $(* p<.05)$ (Table 5$)$. 
Table 5. Comparing abdominal curl-up with expiration in gender status.

\begin{tabular}{|c|c|c|c|c|c|c|}
\hline Muscle & Training Status & $\mathrm{N}$ & M & $\mathrm{SD}$ & $\mathrm{t}$ & $\mathrm{p}$ \\
\hline \multirow{2}{*}{ EO right } & Male & 12 & 32.82 & 9.649 & \multirow{2}{*}{-1.328} & \multirow{2}{*}{.192} \\
\hline & Female & 12 & 37.13 & 10.835 & & \\
\hline \multirow{2}{*}{ EO left } & Male & 12 & 30.69 & 16.037 & \multirow{2}{*}{-3.197} & \multirow{2}{*}{$.003^{*}$} \\
\hline & Female & 12 & 47.66 & 17.511 & & \\
\hline \multirow{2}{*}{ TrA/IO right } & Male & 12 & 25.91 & 9.854 & \multirow{2}{*}{-1.428} & \multirow{2}{*}{.161} \\
\hline & Female & 12 & 30.34 & 9.753 & & \\
\hline \multirow{2}{*}{ TrA/IO left } & Male & 12 & 30.53 & 9.041 & \multirow{2}{*}{-1.445} & \multirow{2}{*}{.157} \\
\hline & Female & 12 & 34.96 & 10.276 & & \\
\hline \multirow{2}{*}{ RA right } & Male & 12 & 30.26 & 8.404 & \multirow{2}{*}{-2.728} & \multirow{2}{*}{$.010^{*}$} \\
\hline & Female & 12 & 37.32 & 7.945 & & \\
\hline \multirow[b]{2}{*}{ RA left } & Male & 12 & 33.51 & 9.143 & \multirow[b]{2}{*}{-.675} & \multirow[b]{2}{*}{.504} \\
\hline & Female & 12 & 35.21 & 6.548 & & \\
\hline \multirow{2}{*}{ SCM right } & Male & 12 & 25.39 & 11.109 & \multirow{2}{*}{-1.181} & \multirow{2}{*}{.245} \\
\hline & Female & 12 & 29.08 & 8.462 & & \\
\hline \multirow{2}{*}{ SCM left } & Male & 12 & 24.75 & 10.562 & \multirow{2}{*}{-.455} & \multirow{2}{*}{.652} \\
\hline & Female & 12 & 26.32 & 11.177 & & \\
\hline
\end{tabular}

There was significantly lower EMG activity of left EO, $29.75 \pm 14.561 \%$ MVIC ; right RA, $28.66 \pm$ $7.537 \%$ MVIC during abdominal curl-up with inspiration in male compared with the EMG activity of left EO, $46.12 \pm 19.744 \%$ MVIC ; right RA, $35.08 \pm 8.425 \%$ MVIC during abdominal curlup with inspiration in female $\left({ }^{*} p<.05\right)$ (Table 6). 
Table 6. Comparing abdominal curl-up with inspiration in gender status.

\begin{tabular}{lllllll}
\hline Muscle & Training Status & $\mathrm{N}$ & $\mathrm{M}$ & $\mathrm{SD}$ & $\mathrm{t}$ & $\mathrm{p}$ \\
\hline \multirow{2}{*}{ EO right } & Male & 12 & 31.88 & 9.144 & & \\
& Female & 12 & 35.24 & 11.351 & -1.030 & .310 \\
EO left & Male & 12 & 29.75 & 14.561 & & \\
& Female & 12 & 46.12 & 19.744 & -2.984 & $.005^{*}$ \\
TrA/IO right & Male & 12 & 23.76 & 8.250 & & \\
& Female & 12 & 28.52 & 10.769 & & \\
TrA/IO left & Male & 12 & 29.29 & 9.154 & & \\
& Female & 12 & 33.54 & 11.668 & & .125 \\
& Male & 12 & 28.66 & 7.537 & & \\
RA right & Female & 12 & 35.08 & 8.425 & & $.015^{*}$ \\
& Male & 12 & 31.79 & 8.630 & & \\
RA left & Female & 12 & 32.82 & 6.709 & & .674 \\
& Male & 12 & 27.32 & 13.282 & & \\
SCM left & Female & 12 & 29.34 & 12.454 & & .628 \\
& Female & 12 & 31.85 & 10.144 & & \\
\hline
\end{tabular}

\section{Discussion}

In this study, activation of abdominal muscles and SCM muscles at different respiration phases during curl-up were compared and differences according to subjects having different sportive capacity and gender were analyzed.

The analysis of the data gathered from all the subjects show that there is higher level of muscle activation in EO right, TrA/IO right, TrA/IO left and RA right during curl-up with expiration than curl-up with inspiration. However, the analysis also shows that the values derived from SCM right and SCM left muscles during curl-up with inspiration is higher than the values in curl-up with expiration. According to the results of the study, sternocleidomastoid muscle in the neck area which has a great role for cervical stabilization during curl-up with inspiration gets more active than it does during curl-up with expiration. In a similar study, Yoon et al. (2014) found that SCM muscle gets more active in slow inspiration than it does in slow expiration. The results of their study resemble ours. These results indicate that the muscle group to be the primary active during curl-up is the muscle group in the abdominal area. Therefore, trying to do curl-up at the moment of contraction by doing inspiration may run a risk for neck and cervical zone. For the health of the neck and cervical zone, doing expiration during curl-up at the moment of contraction makes this area less active, which is important to prevent the area from being forced too much at the following phases of the activity with the increase in tiredness. In one of their study, Nepomuceno et al., (2014) compared SCM muscle in supine position and in normal and forced respiration using EMG, and found SCM muscle to be more active during forced respiration. It was particularly reported that this difference was much more at the moment of inspiration (cycle). This shows that SCM muscle shows different 
contraction rates according to respiratory type not only at the moment of curl-up but also in other body positions.

A comparison of mean values of sedentary and athlete participants during curl-up with expiration show that sedentary subjects have higher contraction rates only with at the RA left muscle. However, there is no significant difference in terms of curl-up with inspiration between muscles when sedentary and athlete participants are compared.

Subjects' being active or sedentary and the respiratory type during curl-up do not change the contraction rates of muscles.

A comparison of the mean values of male and female participants during curl-up with expiration indicates that the values derived from females' EO left and RA right muscles are higher than the values derived from the same muscle group of males. However, when the mean values of male and female participants during curl-up with inspiration are compared, it is seen that the values derived from the same muscle group (EO left and RA right) of females are higher than that of males'.

It is seen that females have more strain in some parts of their abdominal muscles in comparison to males during curl-ups which are done at the same level of intensity and density. However, this difference is found to be at the same level in both respiratory types. Consequently, it can be said that this difference does not change according to respiratory types. It can be supposed that the reason why this difference occurs is that males can tolerate curl-ups more which are done at the same level of intensity and density. As there is no difference between genders and the contraction rates of SCM muscle, no gender-specific suggestions can be made about respiration during curl-up for the health of neck and cervical zone

Ethics Committee Approval: Ethics committee approval was received for this study from the approval was obtained from the local Ethical Committee

Author Contributions: İdea- H.S; Design H.S; Supervision- H.S; Funding- H.S; Materials- H.S.; Data Collection/Data Process- H.S, Analyze or Comment- H.S, Literature Scanning- H.S.; Writer of Paper-H.S.; Critical Review- H.S.

Conflict of Interest: No conflict of interest was declared by the author.

Financial Disclosure: The author declared that this study has received no financial support.

\section{References}

Adams L, Datta AK, Guz A. Synchronization of motor unit firing during different respiratory and postural tasks in human sternocleidomastoid muscle. The Journal of Physiology, 1989:

413:213-231.

Axler CT, McGill SM. Low back loads over a variety of abdominal exercises: searching for the safest abdominal challenge. Medicine \& Science in Sports \& Exercise, 1997: 29: 804-8011.

Beim GM, Giraldo JL, Pincivero DM, Borror MJ, Fu FH. Abdominal strengthening exercises: A comparative EMG study. Journal of Sport Rehabilitation, 1997: 6: 11-20.

Clark GT, Browne PA, Nakano M, Yang Q. Coactivation of sternocleidomastoid muscle during maximum clenching. Journal of Dental Research, 1993: 72: 1499 - 1502.

Critchley DJ, Pierson Z, Battersby G. Effect of pilates mat exercises and conventional exercise programmes on transversus abdominis and obliquus internus abdominis activity: pilot randomized trial. Manual Therapy, 2011: 16: 183-189.

De Luca CJA. Practicum on the Use of sEMG Signals in Movement Sciences. Delsys Inc; 2008.

Criswell E. Cram's Introduction to Surface Electromyography. Second Edition, Jones and Bartlett Publishers; 2011.

Ellis $H$. The ribs and intercostal spaces. Anaesthesia \& Intensive Care Medicine, 2008: 9: 518-519.

Neumann D. Kinesiology of the musculoskeletal system: foundation for physical rehabilitation. 2nd ed. Philadelphia: Mosby; 2009.

Falla DL, Jull GA, Hodges PW. Patients with neck pain demonstrate reduced electromyographic activity of the deep cervical flexor muscles during performance of the craniocervical flexion test. Sine, 2004: 29: 2108-2114.

Foster DN, Fulton MN. Back pain and the exercise prescription. Clinical Journal of Sport Medicine, 1991: 10(1):197-209.

Garcia FJV, Grenier SG, McGill SM. Abdominal muscle response during curl-ups on both stable and labile surfaces. Physical Therapy, 2000: 80: 564-569.

Goldby LJ, Moore AP, Doust J, Trew ME. A randomized controlled trial investigating the efficiency of musculoskeletal physiotherapy on chronic low back disorder. Sine, 2006: 31:1083-1093. 
Hides JA, Lambrecht G, Richardson CA, Stanton WR, Armbrecht G, Pruett C, Damann V, Felsenberg D, Belavy DL. The effects of rehabilitation on the muscles of the trunk following prolonged bed rest. European Spine Journal, 2011: 20: 808-818.

Hildenbrand K, Noble L. Abdominal muscle activity while performing trunk-flexion exercises using the $\mathrm{Ab}$ roller, $\mathrm{AB}$ slide, FitBall, and conventionally performed trunk curls. Journal of Athletic Training, 2004: 39(1): 37-43.

Hodges PW. Core stability exercise in chronic low back pain. Orthopedic Clinics North America, 2003: 34: 245-254.

Janda V, Schmid HJA. Muscles as a pathogenic factor in back pain. Proceedings of the Fourth Conference of the International Federation of Orthopaedic Manipulative Therapists. Christchurch, New Zealand, February, 1980. p. 17-18.

Johannsen F, Remvig L, Kryger P, Beck P, Warmig S, Lybeck K, Dryer V, Larson LH. Exercise for chronic low back pain: A clinical trial. Journal of Orthopedic \& Sports Physical Therapy, 1995: 22(2): 52-59.

Jull GA. Deep cervical flexor muscle dysfunction in whiplash. Journal of Musculoskeletal Paint, 2000: 8: 143-154.

Kelly M, Cardy N, Melvin E, Reddin C, Ward C, Wilson F. The craniocervical flexion test: an investigation of performance in young asymptomatic subjects. Manual Therapy, 2013: 18: 83-86.

Konrad P. The ABC of EMG - A Practical Introduction to Kinesiological Electromyography. Noraxon, Arizona, USA; 2005.

Lahad A, Malter AD, Berg AO, Deyo RA. The effectiveness of four interventions for the prevention of low back pain. Journal of the American Medical Association, 1994: 272: 1286-1291.

McGill SM. Low back exercises: evidence for improving exercise regimens. Physical Therapy, 1998: 78: 754-765.

Nepomuceno VR, Nepomuceno EM, Regalo SCH, Cerqueira EP, Souza RR. Electromyographic study on the sternocleidomastoid and pectoralis major muscle during respiratory activity in humans. Journal of Morphological Science, 2014: 31(2): 98-102.

Norris CM. Abdominal muscle training in sport. British Journal of Sports Medicine, 1993: 27(1): 19-27.
O’Leary S, Falla D, Jull G, Vicenzino B. Muscle specificity in tests of cervical flexor muscle performance. Journal of Electromyography and Kinesiology, 2007: 17:35-40.

Rodriguez AA, Kilkey WJ, Agre JC. Therapeutic exercise in chronic neck and back pain. Archives of Physical Medicine and Rehabilitation, 1992: 73: 870-875.

Sterling M, Jull G, Wright A. Cervical mobilization: concurrent effects on pain, sympathetic nervous system activity and motor activity. Manual Therapy, 2001: 6: 72-81.

Yoon T, Kim K, Cynn H. Slow expiration reduces sternocleidomastoid activity and increases transversus abdominis and internal oblique muscle activity during abdominal curl-up. Journal of Electromyography and Kinesiology, 2014: 24: 228-232.. 